\title{
Ketamine Corrects Stress-Induced Cognitive Dysfunction through JAK2/STAT3 Signaling in the Orbitofrontal Cortex
}

\author{
Michael S Patton', Daniel J Lodge', David A Morilak' and Milena Girotti*,I \\ 'Department of Pharmacology and Center for Biomedical Neuroscience, University of Texas Health Science Center at San Antonio, San Antonio, \\ TX, USA
}

\begin{abstract}
Deficits in cognitive flexibility are prominent in stress-related psychiatric disorders, including depression. Ketamine has rapid antidepressant efficacy, but it is unknown if ketamine improves cognitive symptoms. In rats, 2 weeks chronic intermittent cold (CIC) stress impairs reversal learning, a form of cognitive flexibility mediated by the orbitofrontal cortex (OFC) that we have used previously to model cognitive dysfunction in depression. We have shown that activating JAK2/STAT3 signaling in the OFC rescued the CIC stress-induced reversal learning deficit. Thus, in the present study we determined whether ketamine also corrects the stress-induced reversal learning deficit, and if JAK2/STAT3 signaling is involved in this effect. A single injection of ketamine ( $10 \mathrm{mg} / \mathrm{kg}$, i.p.) $24 \mathrm{~h}$ prior to testing rescued the CIC stressinduced reversal learning deficit. CIC stress decreased JAK2 phosphorylation in the OFC, and ketamine restored pJAK2 levels within $2 \mathrm{~h}$ post injection. The JAK2 inhibitor AG490 given systemically or into the OFC at the time of ketamine injection prevented its beneficial effect on reversal learning. We then tested the role of JAK2/STAT3 in ketamine-induced plasticity in the OFC. Ketamine depressed local field potentials evoked in the OFC by excitatory thalamic afferent stimulation, and this was prevented by JAK2 inhibition in the OFC. Further, in both the OFC and primary cortical neurons in culture, ketamine increased expression of the neural plasticity-related protein Arc, and this was prevented by JAK2 inhibition. These results suggest that the JAK2/STAT3 signaling pathway is a novel mechanism by which ketamine exerts its therapeutic effects on stress-induced cognitive dysfunction in the OFC.

Neuropsychopharmacology (2017) 42, 1220-1230; doi:I0.1038/npp.2016.236; published online 9 November 2016
\end{abstract}

\section{INTRODUCTION}

Cognitive flexibility is the ability to modify established thoughts and behaviors based on feedback from a changing environment. This adaptive executive process is mediated by the prefrontal cortex (PFC) (Merriam et al, 1999), and is impaired in several stress-related psychiatric disorders (Castaneda et al, 2008; Porter et al, 2015), including depression. In depression, negative and perseverative cognitive biases are believed to promote and maintain depressive symptoms (Beck, 2008). Reversal learning is a form of cognitive flexibility mediated in the orbitofrontal cortex (OFC) (Clarke et al, 2008). Patients with OFC lesions show impaired emotional regulation (Bechara et al, 2000), and depressed individuals exhibit structural and functional abnormalities in the OFC, as well as deficits in reversal learning (Drevets, 2007). Chronic stress is a risk factor for

*Correspondence: Dr M Girotti, Department of Pharmacology and Center for Biomedical Neuroscience, University of Texas Health Science Center in San Antonio, Mail Code 7764, 7703 Floyd Curl Drive, San Antonio, TX 78229, USA, Tel: +210 567 4278, Fax: +210 567 4300, E-mail: Girotti@uthscsa.edu

Received 2 June 20 16; revised 12 September 20 I 6; accepted 7 October 2016; accepted article preview online 17 October 2016 depression (Kessler, 1997; Manji et al, 2000). We have shown that rats subjected to chronic intermittent cold (CIC) stress exhibit behavioral changes that model several dimensions of depression, including reversal learning deficits (Lapiz-Bluhm et al, 2009; Lapiz-Bluhm and Morilak, 2010).

Currently available antidepressants, including monoamine reuptake inhibitors, require weeks of treatment for maximal effect (Olchanski et al, 2013), and are relatively ineffective, with only one in three people responding to first-round treatment (Janicak et al, 1997). Further, these drugs have limited efficacy in improving cognitive symptoms (Gonda et al, 2015). Acute infusion of the NMDA receptor antagonist, ketamine, has been shown to have rapid antidepressant effects in treatment resistant patients (Berman et al, 2000; Zarate et al, 2006). Preclinical studies have also demonstrated rapid antidepressant-like effects of ketamine (Jett et al, 2015; Li et al, 2010; Rogóz et al, 2002). However, it is unlikely ketamine will ultimately be widely used as a therapeutic agent owing to its many substantial drawbacks, eg, psychotomimetic properties and abuse liability (Lodge and Mercier, 2015). Therefore, elucidating mechanisms underlying the antidepressant effects of ketamine may inform the development of more effective pharmacotherapies. Ketamine is thought to increase 
glutamate signaling in the hippocampus and PFC (Berton and Nestler, 2006; Duman et al, 2012b; Li et al, 2011), by inhibiting fast-firing GABAergic interneurons, resulting in disinhibition of glutamatergic pyramidal cells (Homayoun and Moghaddam, 2007). A recent study showed that hydroxynorketamine, a metabolite of ketamine, similarly activates glutamate signaling without blocking NMDA receptors (Zanos et al, 2016). Activation of pyramidal cells is then thought to induce synaptic plasticity (Zunszain et al, 2013) via BDNF release (Lepack et al, 2015) and downstream regulation of mRNA translation by mTOR (Hoeffer and Klann, 2010; Li et al, 2010; Proud, 2009).

The JAK/STAT signaling pathway comprises Janus tyrosine kinases (JAKs) and signal transduction activators of transcription proteins (STATs). The canonical signaling cascade involves ligand-mediated activation of a gp130 receptor subunit that promotes autophosphorylation of JAK, which then induces phosphorylation of STAT. The JAK/STAT signaling pathway has been studied primarily in the context of peripheral inflammation (Akira, 1999). DeFraja et al (1998) identified this pathway in the CNS, with higher expression of JAK2/STAT3 isoforms in cortex and hippocampus. We recently demonstrated a role for JAK2/ STAT3 in reversal learning (Donegan et al, 2014). Processes reflecting synaptic plasticity, such as long-term depression (LTD), have been implicated in reversal learning (Duffy et al, 2008), and the JAK2/STAT3 pathway has been shown to be involved in LTD (Nicolas et al, 2012), thus identifying this pathway as a potentially novel therapeutic target for deficits in cognitive flexibility.

In the present study, we first explored whether ketamine corrects the CIC stress-induced deficit in reversal learning, and if so, if this requires JAK2/STAT3 signaling in the OFC. We then investigated whether ketamine induces plasticity in the OFC response to thalamic afferent stimulation, providing a functional substrate for its effect on reversal learning. We then tested whether inhibiting JAK2/STAT3 blocks ketamine-induced plasticity in the OFC. At last, in primary cortical neurons we explored the downstream signaling effects of ketamine-induced JAK2/STAT3 phosphorylation. Portions of this work have been presented in abstract form (Patton et al, 2015).

\section{MATERIALS AND METHODS}

\section{Animals}

A total of 179 adult male Sprague Dawley rats (Harlan, 220$240 \mathrm{~g}$ ) were maintained on a $12 / 12 \mathrm{~h}$ light/dark cycle, with food and water ad libitum. All procedures were consistent with NIH guidelines and approved by the Institutional Animal Care and Use Committee of the University of Texas Health Science Center at San Antonio.

\section{CIC Stress}

CIC stress was conducted as described previously (LapizBluhm et al, 2010). Animals were transported in their home cages into a cold room $\left(4^{\circ} \mathrm{C}\right)$ for $6 \mathrm{~h}$, then returned to housing. This was repeated for 14 consecutive days. Controls remained in the housing room.

\section{Attentional Set-Shifting Test}

The attentional set-shifting test was performed as described previously (Donegan et al, 2014). Figure 1a shows the experimental timeline. One week before testing (ie, day 11 of CIC) animals were food restricted to $14 \mathrm{~g}$ per day. One day after the end of CIC, animals were trained to dig in terracotta pots to retrieve $1 / 4$ Honey Nut Cheerio reward (General Mills, Minneapolis, MN, USA). On day 2, they were trained to locate the reward in the baited pot via cues in two sensory dimensions: an odor applied to the rim of the pot, and the digging medium that filled the pot. On Day 3, animals received acute drug administration (below). The following day, animals were tested on a series of discrimination tasks, in which a criterion of six consecutive correct responses was required to proceed to the next task. In the first task (simple discrimination), animals learned to associate one stimulus dimension (eg, odor) with the reward-baited pot. On the second task (compound discrimination), animals continued to discriminate based on that dimension, and the second irrelevant dimension (eg, digging medium) was introduced as a distractor. For the reversal learning task, the cue/reward association was switched: the previously non-rewarded cue was now positive, and vice versa. The dependent measure was number of trials to meet criterion on the reversal task. Animals that did not dig within $10 \mathrm{~min}$ on six consecutive trials, or did not reach criterion within 50 trials on any task were excluded from analysis.

\section{In Vivo Drug Administration}

For systemic administration, animals received saline $(1 \mathrm{ml} /$ $\mathrm{kg})$, or ketamine $(10 \mathrm{mg} / \mathrm{kg}$, i.p.; Henry Schein Animal Health, Dublin, $\mathrm{OH}$ ), and were tested $24 \mathrm{~h}$ later, or killed 2-12 h later. For microinjections, saline or ketamine ( $2 \mathrm{nmol} / 0.5 \mu \mathrm{l} / \mathrm{side}$ (Fukumoto et al, 2016), were infused into the OFC (from bregma: AP $+2.9 \mathrm{~mm}$, ML $2.6 \mathrm{~mm}$, DV $-5.0 \mathrm{~mm}$ ). In preliminary studies, we established that systemic administration of the JAK2 inhibitor Tryphostin AG490 (10 mg/kg, i.p. Fisher Scientific, Waltham, MA) decreased phospho-JAK2 in the rat OFC for at least $2 \mathrm{~h}$ after administration. As the effect of the inhibitor was transient, (undetectable by $4 \mathrm{~h}$ ), and induction of JAK2/STAT3 in the OFC was not evident in the first $30 \mathrm{~min}$ post-ketamine, we injected AG490 or vehicle (DMSO) 15 min after ketamine to maximize the inhibition of initial JAK2 activation. To test the effects of JAK2 inhibition specifically in the OFC, AG490 $(1.47 \mathrm{ng} / 0.5 \mu \mathrm{l})$ or vehicle $(0.03 \% \mathrm{DMSO})$ were microinjected into OFC immediately prior to systemic injection of ketamine. Rats were tested $24 \mathrm{~h}$ later.

\section{Tissue Collection}

A $2 \mathrm{~mm}$ coronal section was cut $2-4 \mathrm{~mm}$ caudal to the frontal pole. OFC was dissected from the lateral margin of the brain to the medial boundary of the forceps minor, ventral to the forceps minor and dorsal to the rhinal sulcus.

\section{MDT-Evoked Field Potentials in OFC}

Rats were anesthetized with chloral hydrate ( $400 \mathrm{mg} / \mathrm{kg}$, i.p.), and placed in a stereotaxic apparatus. A glass microelectrode 
a

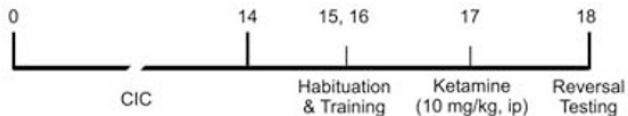

b

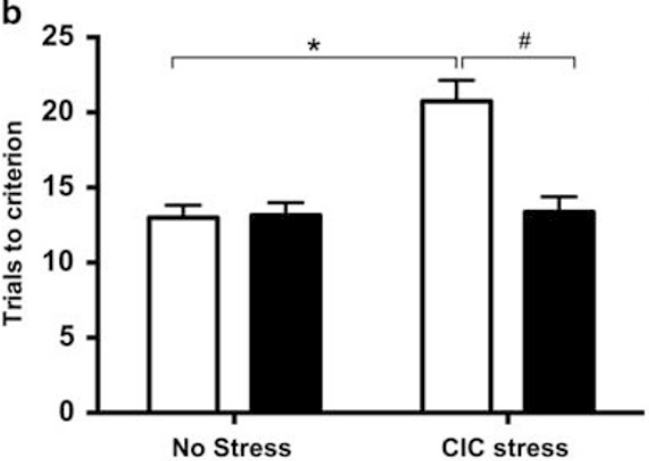

d

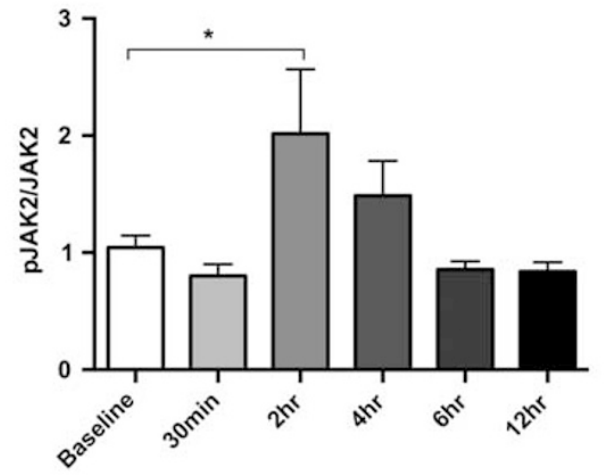

pJAK2

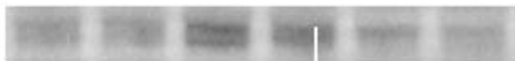

JAK2

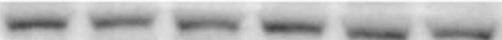

C
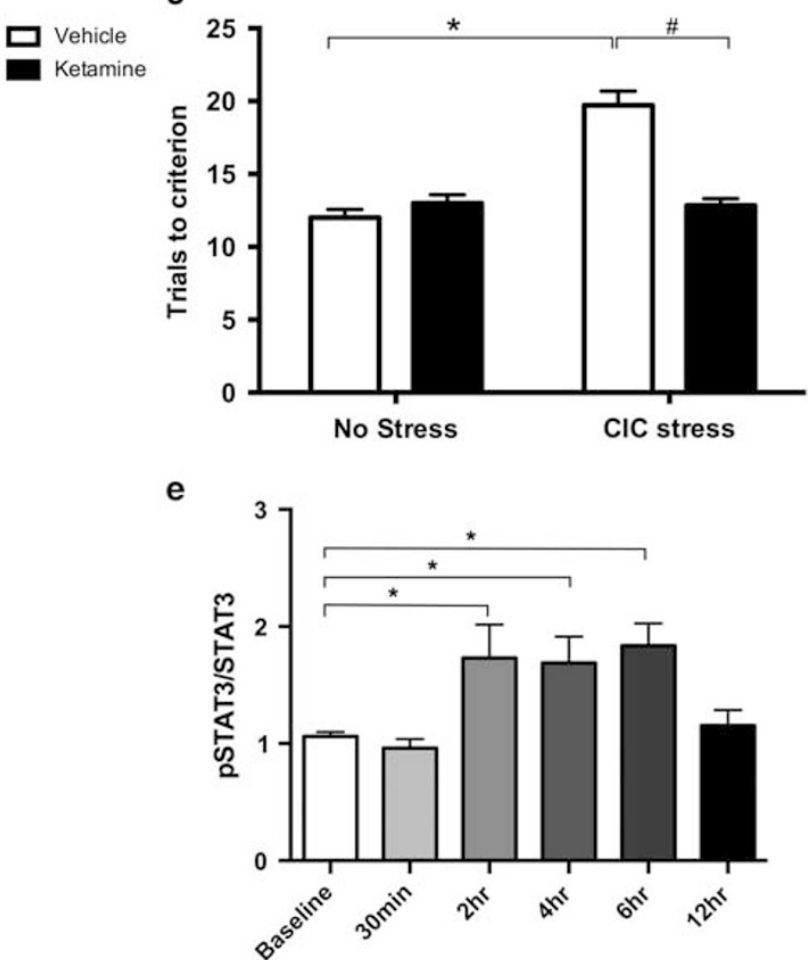

f

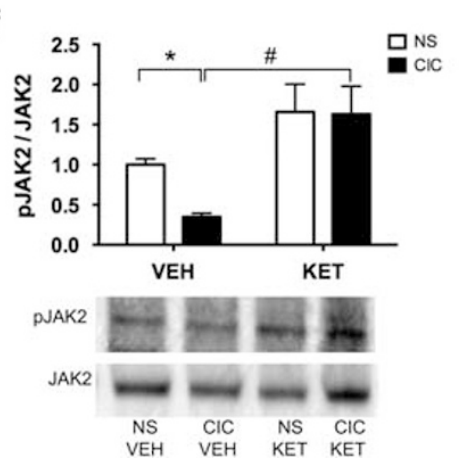

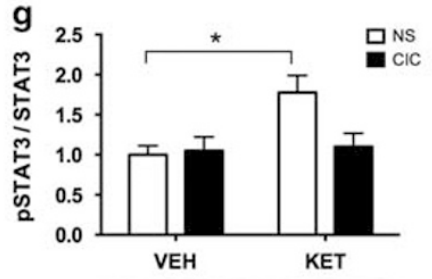

PSTAT3

STAT3

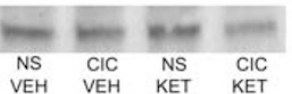

h

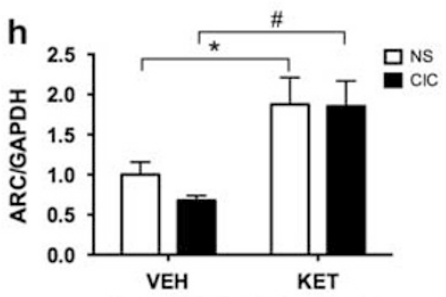

$\begin{array}{cccc}\text { NS } & \text { CIC } & \text { NS } & \text { CIC } \\ \text { VEH } & \text { VEH } & \text { KET } & \text { KET }\end{array}$

Figure I Ketamine corrects the CIC stress-induced cognitive deficit in reversal learning and activates the JAK2/STAT3 pathway in the OFC. (a) Experimental timeline. (b) ClC-stressed rats exhibited a cognitive deficit in reversal learning that was prevented by acute systemic injection of ketamine ( $10 \mathrm{mg} / \mathrm{kg}$, i.p.) given $24 \mathrm{~h}$ prior to testing ( $\mathrm{w}<<0.000 \mathrm{I}, \mathrm{ClC}$ - stressed rats compared with Non-stress control rats given vehicle; $\# p<0.000 \mathrm{I}, \mathrm{ClC}$-stressed rats given ketamine compared with ClC-stressed rats given vehicle; $n=8 /$ group). (c) Local microinjection of ketamine $(2 \mathrm{nmol} / 0.5 \mu \mathrm{l} / \mathrm{side})$ directly into the OFC $24 \mathrm{~h}$ before testing also corrected the $\mathrm{ClC}$ stress-induced reversal learning deficit $* \mathrm{*} p<0.00 \mathrm{I}$, ClC-stressed rats compared with Non-stress control rats given vehicle; $\# p<0.000 \mathrm{I}, \mathrm{ClC}$-stressed rats given ketamine compared with $\mathrm{ClC}$-stressed rats given vehicle; $n=3-7 /$ group. Acute systemic injection of ketamine ( $10 \mathrm{mg} / \mathrm{kg}$, i.p.) increased phosphorylation of both JAK2 (d) and STAT3 (e) in the OFC (* $p<0.05$ compared with baseline; $n=5 / g r o u p)$. ( $f$ ) Three days after the end of CIC stress, levels of pJAK2 were reduced in the OFC $(* p<0.05)$. (g) CIC stress did not change pSTAT3 levels. (h) Levels of the synaptic plasticityrelated protein Arc were modestly reduced after $\mathrm{ClC}$ stress. At $2 \mathrm{~h}$ post injection, ketamine increased expression of Arc in control rats (h; * $<<0.05)$, and increased both pJAK2 (f; $\left.{ }^{\#} p<0.0 \mathrm{I}\right)$ and Arc ( $\left.h ;{ }^{\#} p<0.0 \mathrm{I}\right)$ in CIC-stressed rats, By contrast, ketamine increased pSTAT3 only in controls (* $\left.p<0.05\right)$, but not in $\mathrm{ClC}$-stressed rats ( $n=5-6 /$ group). Values in all figures represent mean \pm SEM. 
was placed into the lateral $\mathrm{OFC}(\mathrm{AP}+3.0 \mathrm{~mm}, \mathrm{ML} 2.8 \mathrm{~mm}$, $\mathrm{DV}-4.5 \mathrm{~mm}$ from brain surface). For local drug administration, a $28 \mathrm{G}$ cannula was positioned $0.3 \mathrm{~mm}$ dorsal to the recording electrode $\left(20^{\circ}\right.$ medial approach: $\mathrm{AP}+3.0 \mathrm{~mm}, \mathrm{ML}$ $0.8 \mathrm{~mm}, \mathrm{DV}-4.5 \mathrm{~mm}$ from the brain surface). A bipolar concentric stimulating electrode (NEX-100, Kopf) was positioned in the mediodorsal thalamus (MDT) (AP $-3.2 \mathrm{~mm}$, ML $0.8 \mathrm{~mm}, \mathrm{DV}-5.0 \mathrm{~mm}$ from brain surface). MDT stimulation evoked a negative field potential in the OFC with a peak latency of $8-15 \mathrm{~ms}$. Test stimuli $(0.1 \mathrm{msec}$, $100-400 \mu \mathrm{A}$ ) were delivered every $30 \mathrm{~s}$. Stimulus intensity was set to evoke $70 \%$ maximal response. Baseline responses were recorded for $15 \mathrm{~min}$. The JAK2 inhibitor AG490 $(1.47 \mathrm{ng} / 0.5 \mu \mathrm{l})$ or vehicle were microinjected into OFC $(0.05 \mu \mathrm{l} / \mathrm{min})$. As microinjection itself produced an approximate $10 \%$ decrease in evoked field potentials that was sustained for the duration of recording, all subsequent measures were compared with a 15 min post microinjection baseline. Ketamine $(10 \mathrm{mg} / \mathrm{kg}$, i.p.) or saline was then administered, and MDT-evoked potentials recorded for $3.5 \mathrm{~h}$. Potentials were amplified, filtered $(0.3-100 \mathrm{~Hz})$ and digitized (ADInstruments power lab) for offline analysis (LabChart 7.1, ADInstruments). Responses were normalized to percent baseline. Changes in evoked responses were analyzed by calculating the mean of all normalized responses in four time bins: baseline, 0-30 $\mathrm{min}, 30-60 \mathrm{~min}$, and 60$210 \mathrm{~min}$ postdrug, generating a single average value for each animal in each bin.

\section{Primary Neuronal Cell Culture}

Cortical neurons were extracted from embryonic day 18 rats, and seeded $\left(2 \times 10^{6}\right.$ cells $\left./ 10 \mathrm{~cm}^{2}\right)$ onto poly-L-lysine-coated plates (Corning) in plating media (Neurobasal supplemented with $2 \mathrm{mM}$ glutamine, $2 \% \mathrm{~B}-27,3 \% \mathrm{FBS}$ ) and maintained in $5 \% \mathrm{CO}_{2}$ at $37^{\circ} \mathrm{C}$. The following day, plating media were replaced with media without FBS, and cells were maintained in serum-free media. Every 3-4 days, media were replaced, and on day 4 , the mitotic inhibitor $\beta$-D-arabinofuranoside (Sigma-Aldrich) was added to curb glial proliferation $(5 \mu \mathrm{M}$ final). Cells were allowed to mature 18 days in vitro before drug administration. On the day of stimulation, cells were incubated with $0.5 \mu \mathrm{M}$ ketamine (Lepack et al, 2015), and lysed at $0-60 \mathrm{~min}$ to establish the time course of treatment effect.

\section{siRNA Transfection}

Rat Accell Smart-pool silencing constructs (GE Dharmacon, Lafayette, CO) were resuspended in $1 \times$ siRNA buffer to a $100 \mu \mathrm{M}$ stock, and stored in aliquots at $-20^{\circ} \mathrm{C}$. Concentrations of the constructs were based on percent knockdown of the target proteins determined in pilot experiments. Primary cortical neurons were transfected with $1 \mu \mathrm{M}$ siRNA constructs, JAK2 (E-088340-00), STAT3 (E-080103-00), or nontargeting pool (D-001910-01) using Accell transfection media (10 $\mu \mathrm{l}: 1 \mathrm{ml}$ media). Cells were incubated in siRNA media for $48 \mathrm{~h}$, then treated for $1 \mathrm{~h}$ with ketamine $(0.5 \mu \mathrm{M})$, or saline. Knockdown efficiency, determined by western blots, was: $\mathrm{JAK} 2=70 \%$, STAT $3=90 \%$.

\section{Fluorescence Immunocytochemistry}

Primary cortical neurons (DIV 18) plated onto poly-lysinecoated glass coverslips were treated with saline or $0.5 \mu \mathrm{M}$ ketamine for $30 \mathrm{~min}$, washed with cold PBS, fixed in $2 \%$ paraformaldehyde for $5 \mathrm{~min}$, then washed and fixed in methanol for $5 \mathrm{~min}$ at $-20^{\circ} \mathrm{C}$. After blocking (1\% BSA, $0.3 \%$ Triton X100, 1\% donkey serum/PBS) for $1 \mathrm{~h}$, cells were incubated with rabbit anti-pJAK2 $\mathrm{mAb}(1: 500$, Millipore 07-606, Billerica, MA) overnight at $4{ }^{\circ} \mathrm{C}$. The next day, coverslips were incubated with biotin-conjugated donkey anti-rabbit secondary antibody for $1 \mathrm{~h}$ and reacted with avidin-peroxidase complex (Vector Laboratories, Burlingame, CA) for $30 \mathrm{~min}$, followed by fluorescein-conjugated tyramide amplification (TSA-Plus, Perkin Elmer, Waltham, MA). After heat inactivation at $70^{\circ} \mathrm{C}$ in $10 \mathrm{mM}$ citric acid, $\mathrm{pH} 6$ for $5 \mathrm{~min}$, coverslips were re-blocked and exposed to mouse anti-Arc mAb (1:2000, Santa Cruz sc-166461, Dallas, TX) overnight at $4{ }^{\circ} \mathrm{C}$. After secondary antibody and $\mathrm{ABC}$ treatment, cells were reacted with a cyanine 3 (cy3)-tagged tyramide or a cyanine 5 (cy5)-tagged tyramide. For triple label, after amplification of the pJAK2 signal, cells were incubated overnight with guinea pig anti-Arc pAb (1:200, Synaptic Systems 156-005), then Alexa-647-conjugated antiguinea pig secondary antibody, followed by DNAseI-Alexa488 (9 $\mu \mathrm{g} / \mathrm{ml}$, Molecular Probes D12371, Eugene, OR), to reveal G-actin. Coverslips were air-dried, mounted with Vectashield (Vector Laboratories) and imaged on an Olympus IX81 inverted confocal microscope using FV10ASW software (Olympus, Tokyo, Japan). Z-sections were captured using a $60 \times$ oil immersion lens. Images represent flattened projections of the $\mathrm{z}$-section stacks. For colocalization analysis, we employed the object-based algorithm in the JACop plug-in of FIJI (ImageJ) software (Bolte and Cordelières, 2006).

\section{Western Blots}

Cell and tissue lysates were prepared in RIPA buffer containing protease and phosphatase inhibitors. Protein content was determined via Bradford assay, and equivalent amounts of protein loaded onto NuPAGE Novex Bis-Tris protein gels (Life Technologies; Grand Island, NY), and electroblotted onto PVDF membranes using iBlot dryblotting system (Life Technologies). Membranes were blocked in TBS-T supplemented with 2\% Amersham ECL Prime Blocking Reagent (GE Healthcare; Pittsburgh, PA), or $5 \%$ BSA. Membranes were incubated overnight at $4{ }^{\circ} \mathrm{C}$ in primary antibody: phospho-STAT3 (Rabbit mAb Tyr705; Cell Signaling 9145; tissue $1: 10000$; cell $1: 1000$ ), phosphoJAK2 (Rabbit pAb Tyr1007/1008;Milipore 07-606; tissue 1:5000; cell 1:2000), Arc (Mouse mAb; Santa Cruz Biotechnology sc-17839; tissue 1:10000; cell 1:2000), GAPDH (Rabbit mAb; Cell Signaling 2118; tissue 1:20000; cell $1: 15000)$. Membranes were incubated in HRPconjugated secondary antibodies for $1 \mathrm{~h}$ at $23^{\circ} \mathrm{C}$, and exposed to Prime ECL detection reagent. Images were captured using the G:BOX-XT4 Chemi system (Syngene; Frederick, MD). Subsequently, membranes were stripped with Restore Plus (Fisher Scientific) and re-probed with antibodies against STAT3 (mouse mAb; Santa Cruz sc-8019; tissue 1:5000; cells $1: 1500$ ), JAK2 (Rabbit mAb; Cell 
Signaling 3230; tissue $1: 10000$; cells $1: 5000)$. Single samples were run from each rat or independent cell culture, and every assay in an experiment included samples from all experimental groups. Data were calculated as percent baseline, and normalized to the corresponding total protein or to a housekeeping protein.

\section{Statistical Analysis}

Data were analyzed by ANOVA, with repeated measures where appropriate. Pairwise comparisons were performed using Newman-Keuls test, or Dunnett's test when comparing multiple time points to a single baseline. Normalized evoked potentials were analyzed non-parametrically by Kruskal-Wallis test, followed by Dunn's test. Significance was determined at $p<0.05$.

\section{RESULTS}

\section{Ketamine Corrects the CIC Stress-Induced Deficit in Reversal Learning}

We first tested whether a single injection of ketamine corrected the stress-induced reversal learning deficit. Rats subjected to CIC stress performed similarly to controls in the simple and compound discrimination tasks, and ketamine did not influence performance on these tasks (main effect for stress: $F_{(1,27)}=1.12, p=0.29$; Drug; $F_{(1,27)}=0.001, p=0.97$; data not shown), indicating no stress- or drug-induced differences in general learning capability prior to the reversal task. On the reversal task, there were significant main effects of stress $\left(F_{(1,27)}=21.38, p<0.001\right)$, drug $\left(F_{(1,27)}=17.55\right.$, $p<0.01)$ and a stress $\times$ drug interaction $\left(F_{(1,27)}=18.96\right.$, $p<0.01$ ). Consistent with previous results (Lapiz-Bluhm and Morilak, 2010), CIC-stressed animals performed worse than non-stressed controls on the reversal learning task, and this deficit was corrected by acute ketamine injection $24 \mathrm{~h}$ before testing (Figure 1b). Ketamine did not affect reversal learning in non-stressed controls. Results were similar when ketamine was injected directly into the OFC (stress: $F_{(1,15)}=17.42, p<0.001$, drug: $F_{(1,15)}=10.57$, $p<0.01$; stress $\times$ drug interaction: $F_{(1,15)}=18.99, p<0.001$, Figure 1c).

\section{Ketamine Activates the JAK2/STAT3 Pathway in OFC}

We then determined whether ketamine administration activated the JAK2/STAT3 pathway in the OFC. Systemic injection of ketamine induced phosphorylation of both JAK2 $\left(F_{(5,51)}=4.34, p<0.01\right.$; Figure $\left.1 \mathrm{~d}\right)$ and STAT3 $\left(F_{(5,57)}=6.31\right.$, $p<0.001$; Figure 1e). JAK2 phosphorylation increased relative to baseline at $2 \mathrm{~h}$ post ketamine $(p<0.05$; Figure 1d). STAT3 phosphorylation was elevated $2-6 \mathrm{~h}$ post ketamine $(p<0.05$; Figure $1 \mathrm{~d})$. In a separate experiment, the effects of ketamine on JAK2/STAT3 phosphorylation in the OFC after CIC stress were then measured $2 \mathrm{~h}$ post ketamine. As above, ketamine increased JAK2 phosphorylation $\left(F_{(1,16)}=18.60, p<0.001\right)$. There was no main effect of stress $\left(F_{(1,16)}=2.22, p=0.16\right)$ nor an interaction $\left(F_{(1,16)}=1.87\right.$, $p=0.19$ ), although pairwise comparisons showed a significant reduction in JAK2 phosphorylation after CIC $(p<0.05)$ that was reversed by ketamine $(p<0.01$, Figure 1f). By contrast, CIC stress alone had no effect on STAT3 phosphorylation (Figure 1g). Replicating the result above, there was a significant effect of drug $\left(F_{(1,17)}=6.28, p<0.05\right)$, and an interaction $\left(F_{(1,16)}=4.81, p<0.05\right)$, as ketamine increased pSTAT3 in controls $(p<0.05)$, but had no effect in CIC-stressed rats. A marginal main effect of Stress $\left(F_{(1,17)}=3.57, p=0.08\right)$ was attributable entirely to this response to ketamine in non-stressed animals.

\section{Pharmacological Inhibition of JAK2/STAT3 Activity in the OFC Abolishes the Beneficial Effect of Ketamine on Reversal Learning}

We tested whether JAK2 inhibition by AG490 during ketamine administration prevented its beneficial effect on stress-induced cognitive dysfunction. As in the previous experiment, there were no effects of any manipulation on the simple or compound discrimination tasks preceding reversal learning (data not shown). On the reversal task, ANOVA revealed significant main effects of Stress $\left(F_{(1,30)}=40.37\right.$, $p<0.001)$ and AG490 $\left(F_{(1,30)}=4.08, p=0.05\right)$, a stress $\times$ ketamine interaction $\left(F_{(1,30)}=5.08, p<0.05\right)$, stress $\times$ AG490 interaction $\left(F_{(1,30)}=10.56, p<0.01\right)$ and ketamine $\times$ AG490 interaction $\left(F_{(1,30)}=9.09, p<0.01\right)$. CIC-stressed animals exhibited a deficit in reversal learning compared with non-stressed vehicle-treated animals $(p<0.05)$ that was corrected by ketamine $(p<0.01)$, and this effect was prevented by inhibition of JAK2 at the time of ketamine administration $(p<0.001$; Figure $2 \mathrm{a})$. We next determined whether JAK2 inhibition specifically in the OFC similarly prevented the beneficial effect of ketamine on reversal learning. Local injection of AG490 had no effect in non-stressed rats compared with vehicle. Cold-stressed rats exhibited the reversal learning deficit $(p<0.001)$, that was again corrected by ketamine $(p<0.001)$. JAK2 inhibition in the OFC with AG490 prevented the beneficial effect of ketamine in cold-stressed animals $(p<0.001$; Figure 2b).

\section{Ketamine-Induced Increases in Levels of the Synaptic Plasticity-Related Protein Arc in the OFC are Prevented by JAK2 Inhibition}

Previous work has shown that ketamine increases expression of the synaptic protein Arc in the mPFC, which may underlie its effects on synaptic plasticity. Here we determined whether ketamine administration similarly increased expression of Arc in the OFC, and if inhibition of JAK2 with AG490 prevented ketamine-induced Arc expression. Ketamine increased Arc in the OFC $\left(F_{(5,34)}=3.61, p<0.05\right.$; Figure 2c), which was significant relative to baseline at $2 \mathrm{~h}$ post ketamine $(p<0.01)$. Systemic administration of AG490 prevented Arc induction by ketamine $(p<0.05$; Figure $2 d)$. In a separate experiment, Arc levels showed a modest nonsignificant reduction in CIC-stressed rats. Ketamine increased Arc levels in the OFC of both CIC-stressed $(p<0.01)$ and control rats $(p<0.05$, Figure $1 \mathrm{~h})$. 
a

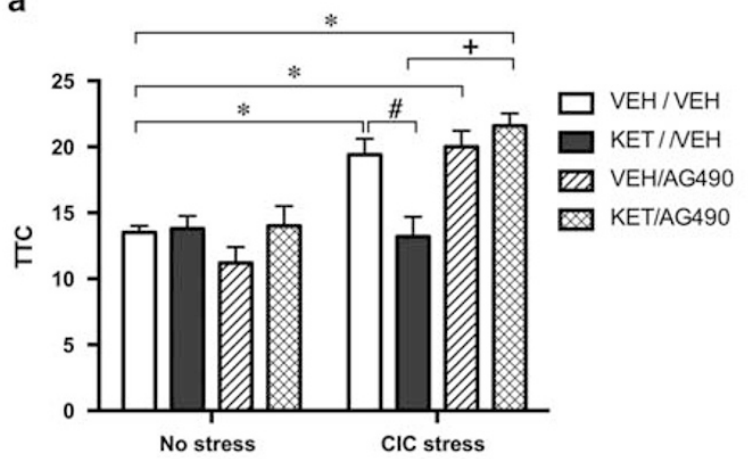

C

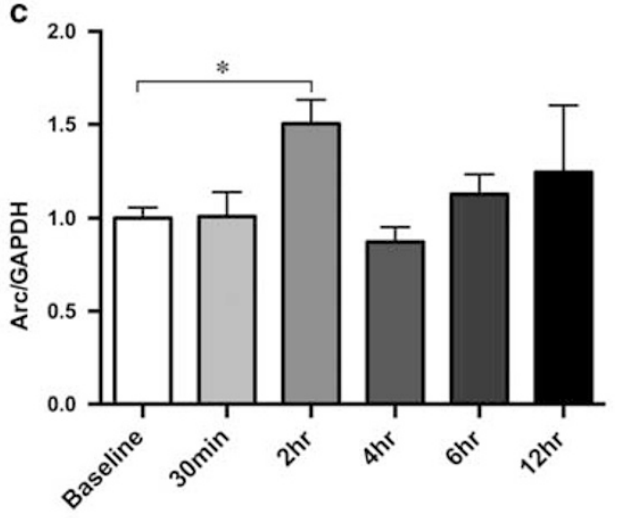

Arc

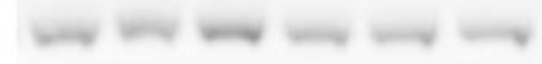

GAPDH b

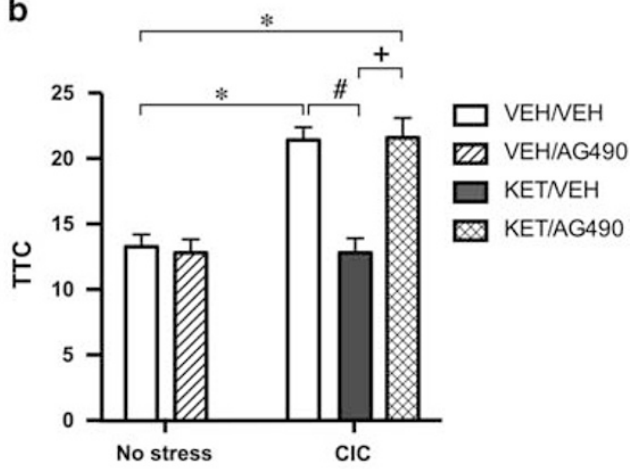

d
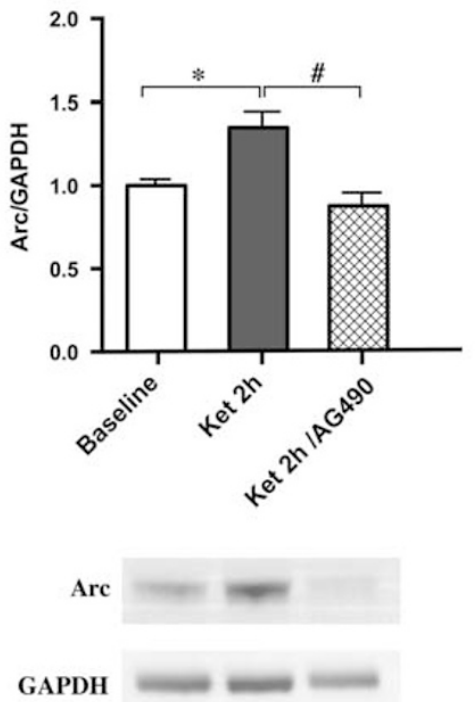

Figure 2 Pharmacological inhibition of the JAK2/STAT3 pathway in the OFC prevents the beneficial effects of ketamine on reversal learning and induction of the plasticity-related protein Arc. (a) Systemic administration of the JAK2 inhibitor AG490 (I $0 \mathrm{mg} / \mathrm{kg}$, i.p.) at the time of ketamine administration blocked the beneficial effect of ketamine on reversal learning in ClC-stressed rats, tested $24 \mathrm{~h}$ after injection $\left(* p<0.05\right.$ compared with non-stressed-vehicle; ${ }^{\#} p<0.0$ I compared with $\mathrm{ClC}$ vehicle; $+p<0.00$ I compared with ClC-ketamine; $n=5 / g r o u p)$. (b) Local microinjection of AG490 (I.47 ng/0.5 $\mu \mathrm{l})$ in the OFC similarly prevented the beneficial effect of ketamine in CIC-stressed animals $\left(* p<0.001\right.$ compared with non-stressed vehicle/vehicle; ${ }^{\#} p<0.001$ compared with CIC vehicle/vehicle; $+p<0.00$ I compared with ClC-ketamine-vehicle; $n=4-5 /$ group). (c) Ketamine increased the expression of the synaptic plasticity-related protein Arc in the OFC $2 \mathrm{~h}$ after administration ${ }^{*} p<0.05$ compared with baseline; $n=5-8 /$ group). (d) Pre-treatment with AG490 prevented ketaminemediated induction of Arc protein in the OFC at $2 \mathrm{~h}\left({ }^{*} p<0.05\right.$ compared with baseline; ${ }^{\#} p<0.05$ compared with Ket- $2 \mathrm{~h} ; n=5 /$ group). Values represent mean \pm SEM.

\section{Ketamine Administration Induces Functional Plasticity in the OFC that is Dependent on JAK2 Kinase Activity}

We next tested the functional effects of ketamine administration on afferent-evoked local field potential (LFP) responses in OFC, and if JAK2 inhibition in OFC prevented these effects. Animals pre-treated with a local microinjection of ACSF $(0.05 \mu \mathrm{l} / \mathrm{min}, 0.5 \mu \mathrm{l}$ total injection volume) followed by systemic injection of saline exhibited a stable LFP response for the $210 \mathrm{~min}$ duration of the experiment (mean $=101.7 \pm 5.8 \%$; Figure $3 \mathrm{a})$. In rats pre-treated with ACSF in OFC, systemic injection of ketamine induced a depression of the evoked LFP $\left(H_{(3)}=12.94, p<0.05\right)$ that was first evident $30-60 \mathrm{~min}$ after injection (mean $=80.8 \pm 8.5 \%$, $p<0.05$ compared with baseline), and remained stable for the duration of recording, 60-210 min post injection (mean $=69.5 \pm 7.3 \% ; \quad p<0.01$ compared with baseline; Figure 3b). Pre-treatment with a microinjection of the JAK2 inhibitor AG490 into OFC, followed by systemic vehicle injection had no effect on evoked LFPs at any time after injection $\left(H_{(3)}=1.92, p=0.64\right.$; Figure $\left.3 c\right)$. By contrast, microinjection of AG490 into OFC prevented the ketamineinduced depression of the evoked response (mean $=100.4$ $+9.1 \%$ at $30-60 \mathrm{~min}$ and $104.7 \pm 14.1 \%$ at $60-210 \mathrm{~min}$; $H_{(3)}=0.58, p=0.90$; Figure $\left.3 \mathrm{~d}\right)$.

Inhibition of JAK2 but not STAT3 Blocks Induction of the Synaptic Plasticity-Related Protein Arc in Primary Cortical Neurons

We next used an in vitro system to elucidate the roles of JAK2 and/or STAT3 in ketamine-induced Arc expression. Treatment of primary cortical neurons in culture with 

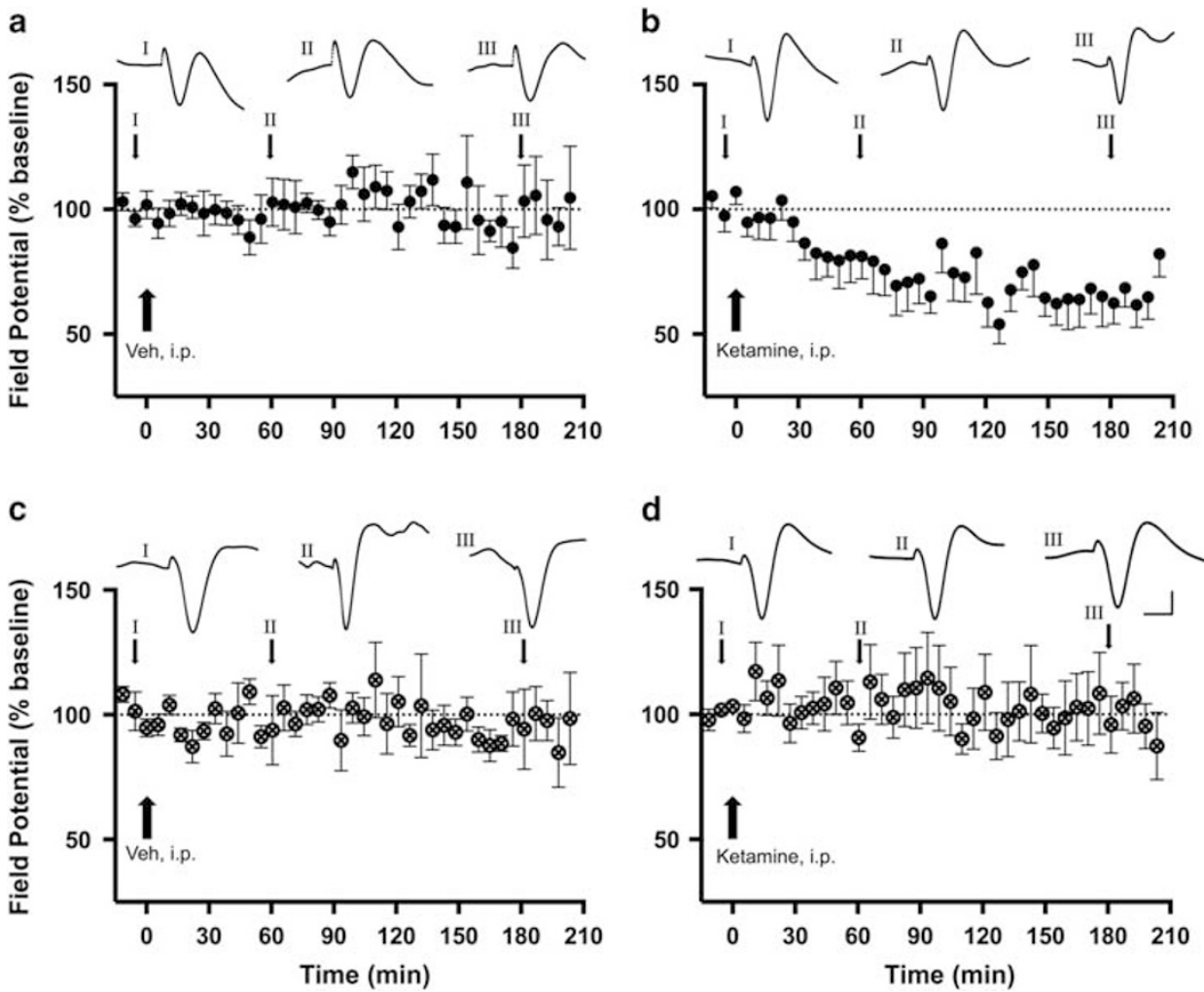

Figure 3 Systemic ketamine administration depresses evoked field potentials in the OFC, and this is prevented by inhibiting JAK2 activity in the OFC. In rats receiving a microinjection of ACSF vehicle $(0.5 \mu \mathrm{l})$ into OFC, a subsequent systemic saline injection had no effect on evoked LFP responses in the OFC (a), whereas systemic ketamine administration ( $10 \mathrm{mg} / \mathrm{kg}$, i.p.) induced a depression of the evoked LFP response that emerged 30-60 min after injection and lasted for the duration of recording (b). Local microinjection of the JAK2 inhibitor AG490 into OFC prior to a systemic injection of saline had no effect on the evoked LFP alone (c), but prevented the ketamine-induced depression of the evoked LFP (d). Insets show representative traces recorded at the time points indicated. Data represent mean percent of baseline \pm SEM ( $n=5 /$ group $)$.

ketamine $(0.5 \mu \mathrm{M})$ induced phosphorylation of both JAK2 $\left(F_{(4,25)}=6.94, p<0.01\right.$; Figure $\left.4 \mathrm{a}\right)$ and STAT3 $\left(F_{(4,20)}=3.24\right.$, $p<0.05$; Figure $4 \mathrm{~b}$ ). Peak phosphorylation of both proteins occurred $30 \mathrm{~min}$ after drug application, and the elevated phosphorylation of JAK2 persisted for at least $60 \mathrm{~min}$. Ketamine also increased expression of the synaptic protein $\operatorname{Arc}\left(F_{(4,35)}=5.42, p<0.01\right.$; Figure $\left.4 \mathrm{c}\right)$, with peak elevation $60 \mathrm{~min}$ after administration. We next investigated whether the increase in Arc protein expression was attributable to STAT3 transcriptional activity or to non-transcriptional JAK2 kinase activity. Baseline Arc expression was reduced in JAK2-silenced cells relative to vehicle-treated controls $(p<0.01)$, but was unaffected in STAT3-silenced cells. Ketamine increased Arc expression in primary neurons treated with control RNA $(p<0.05)$, and this was prevented by JAK2 knockdown $(p<0.001$; Figure $4 \mathrm{~d})$.

\section{Phosphorylated JAK2 Colocalizes with Arc after Ketamine Treatment}

We next investigated whether pJAK2 was present in active dendritic spines, where synaptic Arc expression is thought to be involved with AMPAR cycling. In both vehicle- and ketamine-treated primary cortical neurons, phosphorylated JAK2 was colocalized with Arc protein (Figure 5a and b). Quantitative analysis showed that upon ketamine treatment, the percent of pJAK2 colocalized with Arc significantly increased, whereas the percent of Arc colocalized with pJAK2 decreased (Figure 5c). Further, colocalization of pJAK2 and Arc was observed in a subset of punctate structures that were also positive for monomeric G-actin (Figure 5d), which is enriched in active dendritic spines (Lei et al, 2016).

\section{DISCUSSION}

In this study, a single injection of ketamine corrected the reversal learning deficit induced by CIC stress $24 \mathrm{~h}$ after injection. Microinjection of ketamine directly into the OFC was also effective, indicating that the beneficial effects of ketamine on reversal learning are at least in part owing to actions in the OFC. We previously showed that ketamine corrects a cognitive set-shifting deficit caused by chronic unpredictable stress, another form of cognitive flexibility dependent on the medial PFC (Jett et al, 2015). Collectively, these results demonstrate that ketamine impacts multiple cortical circuits involved in cognitive flexibility and implicated in stress-induced cognitive dysfunction.

Recently we showed that activating the JAK/STAT pathway in the OFC similarly corrected the CIC stress-induced reversal learning deficit (Donegan et al, 2014). Therefore, we tested whether ketamine administration activates the JAK2/ STAT3 pathway as a mechanism in its beneficial effects on reversal learning. Ketamine induced JAK2 and STAT3 


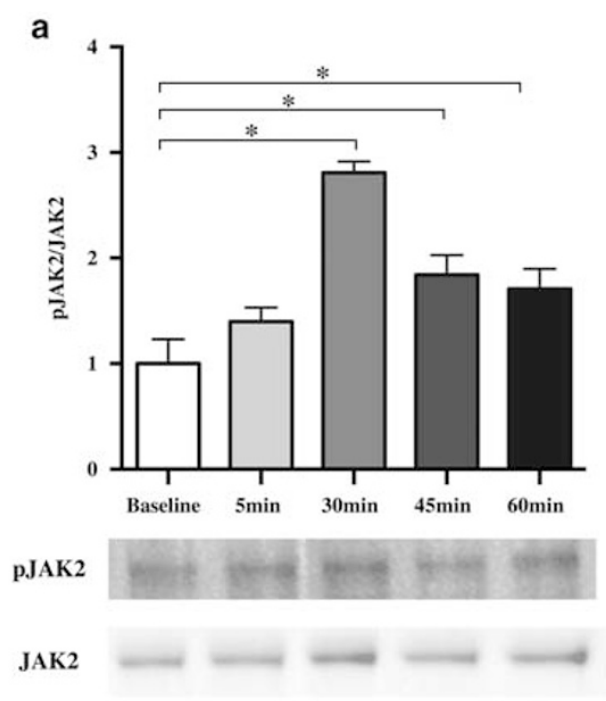

C

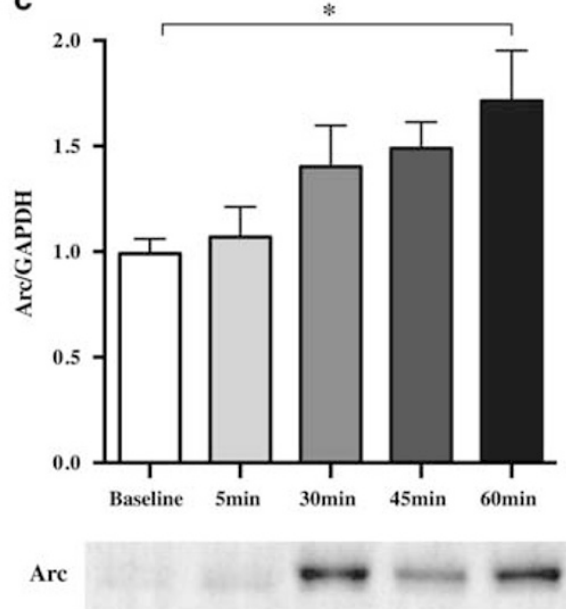

GAPDH b

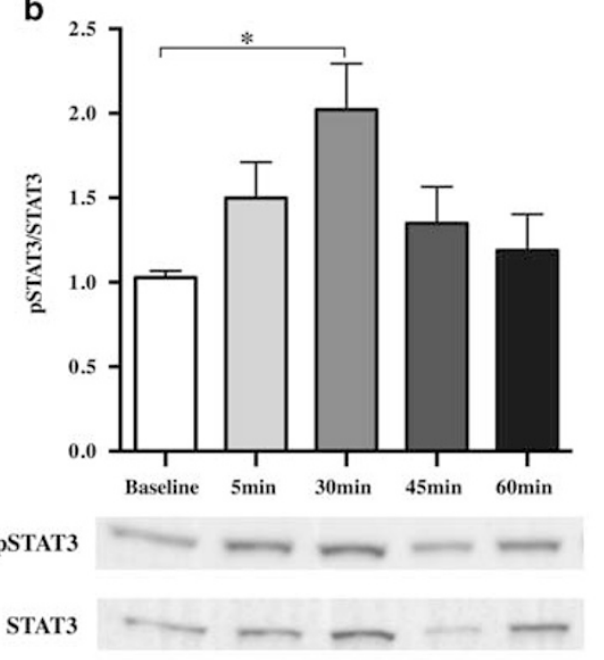

d
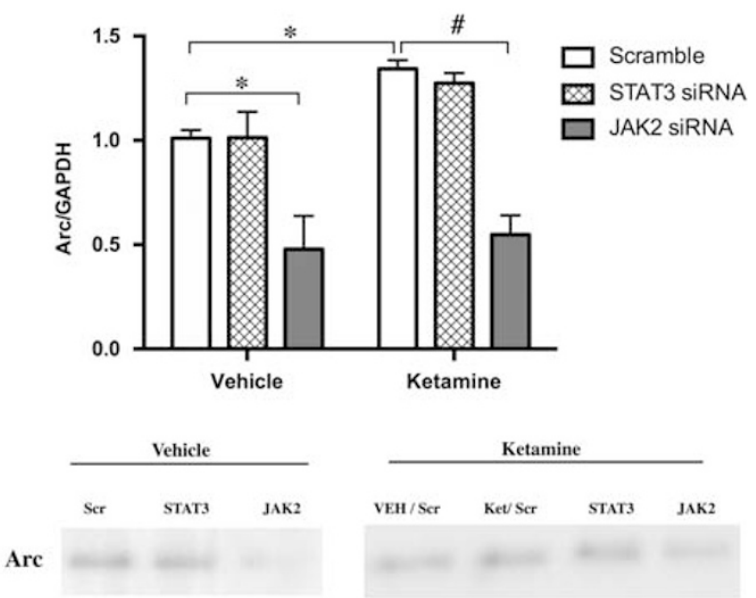

GAPDH

Figure 4 Ketamine administration induces phosphorylation of JAK2 and STAT3 in rat primary cortical neurons in culture, and blocking JAK2 but not STAT3 prevents ketamine-induced Arc expression. Ketamine administration ( $0.5 \mu \mathrm{M}$ ) induced phosphorylation of both JAK2 (a) and STAT3 (b) within 30 min of drug application (* $p<0.01$ compared with baseline). (c) Ketamine administration $(0.5 \mu \mathrm{M})$ increased expression of the synaptic plasticity-related protein Arc 60 min after administration ( ${ }^{p}<0.01$ compared with baseline). (d) siRNA knockdown of JAK2, but not STAT3, reduced basal Arc expression and prevented the ketamine-induced increase in Arc expression ${ }^{*} p<0.01$ compared with baseline; ${ }^{\#} p<0.00$ I compared with scrambled-ketamine). Values represent mean \pm SEM ( $n=4-7$ independent cultures per time point).

phosphorylation in the OFC of unstressed rats, and restored levels of pJAK2 reduced by CIC stress. Blocking this pathway during ketamine administration abolished the beneficial effect on reversal learning, whether the JAK2 inhibitor AG490 was injected systemically or directly into OFC. This suggests that, in addition to the well-documented activation of mTOR and BDNF/TrkB (Autry et al, 2011; Li et al, 2010), activation of JAK2/STAT3 represents another mechanism by which ketamine exerts its therapeutic effects, at least on processes mediated in the OFC.

Neuroimaging studies have revealed dysfunction in limbicthalamo-cortical circuits in depressed patients (Drevets, 2001), and preclinical studies have shown dendritic destabilization in the hippocampal-prefrontal-cortical circuit in rodent models of depression (Duman and Aghajanian, 2012a). Ketamine corrected both stress-induced dendritic atrophy and depressive-like behaviors (Li et al, 2011). In the present study, ketamine depressed afferent-evoked field potentials in the OFC, which contrasts with potentiated responses reported in the MPFC (Li et al, 2011), indicating that ketamine may differentially affect plasticity in these two regions. These seemingly contradictory observations can perhaps be reconciled by another study showing that chronic stress-induced retraction of dendrites in the mPFC, but increased dendritic arborization in the OFC (Liston et al, 2006). Thus, it is possible that ketamine exerts different effects on synaptic function that has been differentially compromised by stress in these two regions. 

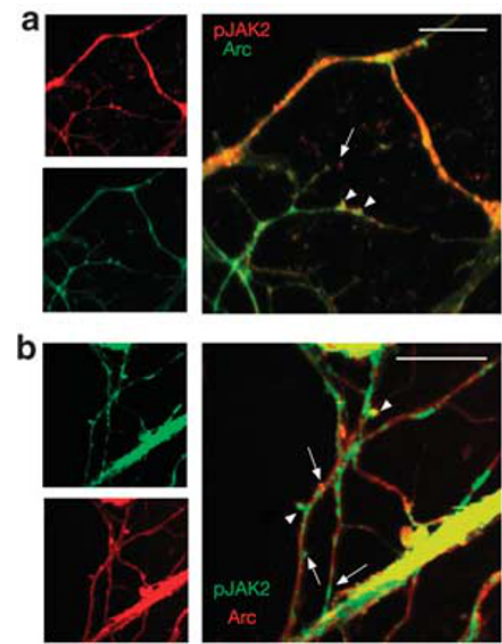
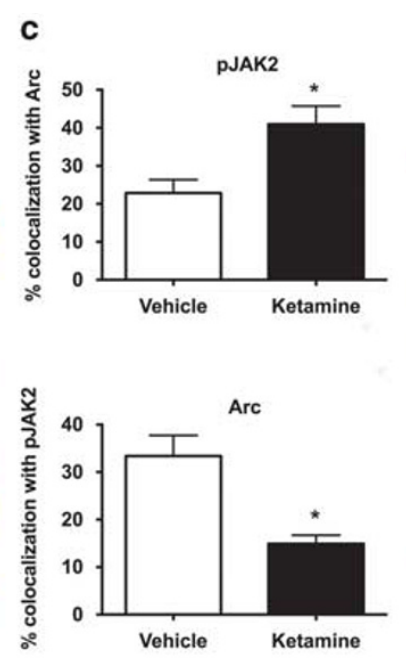

d

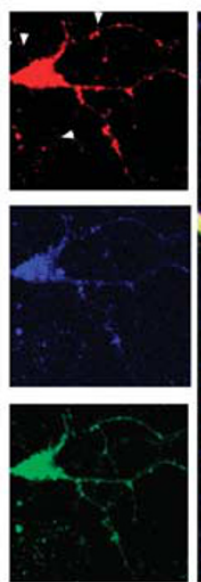

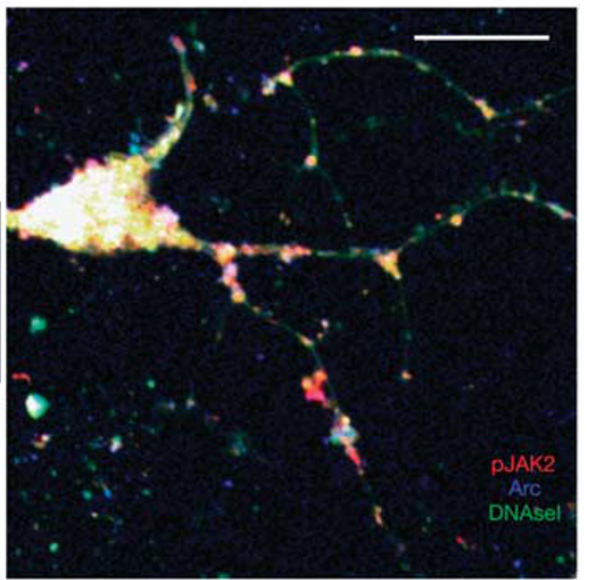

Figure 5 Phosphorylated JAK2 colocalizes with Arc. EI 8 rat cortical neurons (DIV I8) were stimulated with $0.5 \mu M$ ketamine or saline vehicle for 30 min prior to fixation and processing for immunofluorescence. Phosphorylated JAK2 (pJAK2) was colocalized with Arc in a subset of punctate structures in both vehicle- (a) and ketamine-treated (b) neurons. Arrowheads indicate puncta where the two proteins are colocalized. Full arrows indicate non-colocalized Arc or pJAK2. Bar $=20 \mu \mathrm{m}$. (c) Quantification of colocalization of pJAK2 and Arc in vehicle- and ketamine-treated neurons. After ketamine stimulation, the percentage of pJAK2 signal colocalized with Arc increased $(* p<0.01)$, whereas the percentage of total Arc signal colocalized with $p J A K 2$ decreased $(* 0<0.00$ I); unpaired Student's $t$-test; $n=9$ fields analyzed from three independent cultures. (d) G-actin (visualized with DNAsel stain, green) is also present at sites where pJAK2 (red) and Arc (blue) colocalize. Arrowheads indicate triple-labeled puncta. Bar $=20 \mu \mathrm{m}$.

Pre-treatment with the JAK2 inhibitor, AG490, prevented the depression of evoked LFPs in the OFC by ketamine, consistent with recent evidence that the JAK/STAT3 pathway is required for the induction and maintenance of LTD (Nicolas et al, 2012). The fact that ketamine depressed evoked responses in the OFC and corrected the reversal learning deficit agrees with previous work demonstrating the importance of LTD in reversal learning (Duffy et al, 2008). Associative conditioning and persistence of memories for learned contingencies has been attributed to long-term potentiation (Luscher et al, 2000). Thus, it is possible that ketamine, by reducing afferent-evoked responses in the OFC, establishes a functional state conducive to cognitive flexibility, the ability to modify previously learned contingencies. Future experiments will determine whether ketaminemediated depression of evoked responses persists for $24 \mathrm{~h}$, ie, the time of behavioral testing, and if CIC stress alters afferent-evoked responses in the OFC.

Ketamine has been shown to induce the synaptic plasticity-related protein Arc ( $\mathrm{Li}$ et al, 2010), which is involved in AMPA receptor internalization associated with LTD (Shepherd and Bear, 2011; Bramham et al, 2008). Arc localizes to active synapses and interacts with endocytotic machinery to promote internalization of GluA1 and GluA2 receptors (Chowdhury et al, 2006), giving rise to different forms of LTD (Park et al, 2008; Plath et al, 2006). Given the role of JAK/STAT in LTD (Nicolas et al, 2012), we postulated that Arc may be a target of JAK/STAT signaling. We showed that ketamine increased expression of Arc in the OFC of both non-stressed and CIC-stressed rats, and pre-treatment with the JAK2 inhibitor AG490 prevented this increase. Pharmacological inhibition of JAK2 affects both JAK and STAT activity, so we used siRNA in primary cortical neurons to determine whether JAK2/STAT3 regulation of Arc expression was due to JAK2 kinase activity or transcriptional activity of STAT3. Ketamine increased JAK2 and STAT3 phosphorylation in primary cortical neurons. Although JAK2 phosphorylation remained elevated for at least $1 \mathrm{~h}$ after ketamine administration, STAT3 phosphorylation returned to baseline more quickly, perhaps owing to negative feedback proteins such as the suppressor of cytokine signaling protein 3 (Heinrich et al, 2003; Heinrich et al, 1998). Arc expression also increased, consistent with previous reports ( $\mathrm{Li}$ et al, 2010). Silencing JAK2, but not STAT3 reduced basal levels of Arc, and prevented the increase in Arc expression by ketamine. These results suggest that JAK2-STAT3 signaling is involved in ketamine-induced increases in Arc expression, but that this involves mechanisms other than STAT3dependent transcriptional effects, perhaps implicating JAK2 kinase activity. This was further supported by the observation that CIC stress differentially affected JAK2 and STAT3 phosphorylation in the OFC, and Arc expression more closely mirrored changes in pJAK2.

Arc turnover is rapid, with regulation of both transcription/translation (Waltereit et al, 2001) and proteosomal degradation (Mabb et al, 2014). JAK2 has been shown to activate de-ubiquitinating enzymes (Jaster et al, 1997) that could inhibit ubiquitin-mediated degradation of Arc. Other studies have shown that factors involved in protein translation as well as ubiquitination localize to dendritic spines (Mabb et al, 2014; Steward et al, 1998), consistent with the possibility that pJAK2 may regulate the expression of Arc in spines. In support of this, we found that ketamineactivated JAK2 colocalized with Arc in punctate structures we assume to be spines on the dendrites of cultured cortical neurons. These structures were characterized by the presence of monomeric G-actin, which has been shown to localize to the heads of dendritic spines undergoing activity-dependent remodeling (Lei et al, 2016). After ketamine, the proportion of pJAK2 colocalized with Arc was increased, suggesting that 
acutely activated JAK2 may have a role in stimulating Arc activity. By contrast, the proportion of total Arc protein colocalized with pJAK2 decreased after ketamine, which may reflect the fact that newly synthesized Arc may distribute widely throughout the cell.

The mechanism by which ketamine activates JAK2/STAT3 remains to be understood. Ketamine increases intracellular calcium by activating voltage-dependent calcium channels, which mediates both BDNF release and the antidepressant effects of ketamine on the forced swim test (Lepack et al, 2015). Increases in intracellular calcium have also been shown to induce JAK2 phosphorylation (Frank et al, 2002), suggesting that ketamine may activate JAK2/STAT3 through calcium influx.

In summary, these data show that ketamine activates JAK2/STAT3 in the OFC, producing a depression of afferent-evoked responses. This contributes to the beneficial effects of ketamine in restoring cognitive flexibility that has been compromised by chronic stress. Ketamine has garnered considerable interest as a rapidly acting antidepressant, with efficacy in treatment resistant patients (DiazGranados et al, 2010). However, ketamine has many significant drawbacks that limit its potential therapeutic utility (Lodge and Mercier, 2015). Identifying mechanisms underlying its beneficial effects may suggest new strategies for the treatment of depression. The present results suggest that the JAK2/STAT3 signaling pathway is a viable candidate for further investigation as a potential therapeutic target.

\section{FUNDING AND DISCLOSURE}

This work was supported by research grants R21MH100652 (MG) and R01MH053851 (DAM) from the National Institute of Mental Health. We thank Drs Gek Ming Sia and Kelly Berg, UTHSCSA Department of Pharmacology, for sharing their expertise and facilities for the primary cortical neuron culture experiments. Dr Morilak serves on a Psychopharmacology advisory board for $\mathrm{H}$ Lundbeck A/S, and receives research funding from Lundbeck Research USA. These activities have no relation to any of the work presented in this paper. Mr Patton, Dr Girotti, and Dr Lodge have no competing financial interests to disclose.

\section{REFERENCES}

Akira S (1999). Functional roles of STAT family proteins: lessons from knockout mice. Stem Cells 17: 138-146.

Autry AE, Adachi M, Nosyreva E, Na ES, Los MF, Cheng PF et al (2011). NMDA receptor blockade at rest triggers rapid behavioural antidepressant responses. Nature 475: 91-95.

Bechara A, Tranel D, Damasio H (2000). Characterization of the decision-making deficit of patients with ventromedial prefrontal cortex lesions. Brain 123(Pt 11): 2189-2202.

Beck AT (2008). The evolution of the cogntive model of depression and its neurobiological correlates. Am J Psychiatry 165: 969-977.

Berman RM, Cappiello A, Anand A et al (2000). Antidepressant effects of ketamine in depressed patients. Soc Biol Psychiatry 47: 351-354.

Berton O, Nestler EJ (2006). New approaches to antidepressant drug discovery: beyond monoamines. Nat Rev Neurosci 7: 137-151.

Bolte S, Cordelières FP (2006). A guided tour into subcellular colocalization analysis in light microscopy. J Microsc 224: 213-232.
Bramham CR, Worley PF, Moore MJ, Guzowski JF (2008). The immediate early gene arc/arg3.1: regulation, mechanisms, and function. J Neurosci 28: 11760-11767.

Castaneda AE, Tuulio-Henriksson A, Marttunen M, Suvisaari J, Lonnqvist J (2008). A review on cognitive impairments in depressive and anxiety disorders with a focus on young adults. J Affect Disord 106: 1-27.

Chowdhury S, Shepherd JD, Okuno H, Lyford G, Petralia RS, Plath $\mathrm{N}$ et al (2006). Arc/Arg3.1 interacts with the endocytic machinery to regulate AMPA receptor trafficking. Neuron 52: 445-459.

Clarke HF, Robbins TW, Roberts AC (2008). Lesions of the medial striatum in monkeys produce perseverative impairments during reversal learning similar to those produced by lesions of the orbitofrontal cortex. J Neurosci 28: 10972-10982.

De-Fraja C, Conti L, Magrassi L, Govoni S, Cattaneo E (1998). Members of the JAK/STAT proteins are expressed and regulated during development in the mammalian forebrain. J Neurosci Res 54: 320-330.

DiazGranados N, Ibrahim LA, Brutsche NE, Ameli R, Henter ID, Luckenbaugh DA et al (2010). Rapid resolution of suicidal ideation after a single infusion of an N-methyl-D-aspartate antagonist in patients with treatment-resistant major depressive disorder. J Clin Psychiatry 71: 1605-1611.

Donegan JJ, Girotti M, Weinberg MS, Morilak DA (2014). A novel role for brain interleukin-6: facilitation of cognitive flexibility in rat orbitofrontal cortex. J Neurosci 34: 953-962.

Drevets WC (2001). Neuroimaging and neuropathological studies of depression. Curr Opin Neurobiol 11: 240-249.

Drevets WC (2007). Orbitofrontal cortex function and structure in depression. Ann N Y Acad Sci 1121: 499-527.

Duffy S, Labrie V, Roder JC (2008). D-serine augments NMDANR2B receptor-dependent hippocampal long-term depression and spatial reversal learning. Neuropsychopharmacology 33: 1004-1018.

Duman RS, Aghajanian GK (2012a). Synaptic dysfunction in depression: potential therapeutic targets. Science 338: 68-72.

Duman RS, Li N, Liu R-J, Duric V, Aghajanian G (2012b). Signaling pathways underlying the rapid antidepressant actions of ketamine. Neuropharmacology 62: 35-41.

Frank GD, Saito S, Motley ED, Sasaki T, Ohba M, Kuroki T et al (2002). Requirement of $\mathrm{Ca}(2+)$ and PKCdelta for Janus kinase 2 activation by angiotensin II: involvement of PYK2. Mol Endocrinol 16: 367-377.

Fukumoto K, Iijima M, Chaki S (2016). The antidepressant effects of an $\mathrm{mGlu} 2 / 3$ receptor antagonist and ketamine require AMPA receptor stimulation in the $\mathrm{MPFC}$ and subsequent activation of the 5-HT neurons in the DRN. Neuropsychopharmacology 41: 1046-1056.

Gonda X, Pompili M, Serafini G, Carvalho AF, Rihmer Z, Dome P (2015). The role of cognitive dysfunction in the symptoms and remission from depression. Ann Gen Psychiatry 14: 1-7.

Heinrich PC, Behrmann I, Haan S, Hermanns HM, Muller-Newen G, Schaper F (2003). Principles of interleukin (IL)-6-type cytokine signalling and its regulation. Biochem J 374(Pt 1): 1-20.

Heinrich PC, Behrmann I, Muller-Newen G, Schaper F, Graeve L (1998). Interleukin-6-type cytokine signalling through the gp130/Jak/STAT pathway. Biochem J 334(Pt 2): 297-314.

Hoeffer CA, Klann E (2010). mTOR signaling: at the crossroads of plasticity, memory and disease. Trends Neurosci 33: 67-75.

Homayoun H, Moghaddam B (2007). NMDA receptor hypofunction produces opposite effects on prefrontal cortex interneurons and pyramidal neurons. J Neurosci 27: 11496-11500.

Janicak PG, Davis JM, Preskorn SH, Ayd FJ (1997). Principles and Practice of Psychopharmacotherapy, 2nd edn. Williams \& Wilkins: Baltimore, 243-356pp.

Jaster R, Zhu Y, Pless M, Bhattacharya S, Mathey-Prevot B, D'Andrea AD (1997). JAK2 is required for induction of the murine DUB-1 gene. Mol Cell Biol 17: 3364-3372. 
Jett JD, Boley AM, Girotti M, Shah A, Lodge DJ, Morilak DA (2015). Antidepressant-like cognitive and behavioral effects of acute ketamine administration associated with plasticity in the ventral hippocampus to medial prefrontal cortex pathway. Psychopharmacology (Berl) 232: 3123-3133.

Kessler RC (1997). The effects of stressful life events on depression. Annu Rev Psychology 48: 191-214.

Lapiz-Bluhm MDS, Soto-Piña AE, Hensler JG, Morilak DA (2009). Chronic intermittent cold stress and serotonin depletion induce deficits of reversal learning in an attentional set-shifting test in rats. Psychopharmacology 202: 329-341.

Lapiz-Bluhm S, Morilak DA (2010). A cognitive deficit induced in rats by chronic intermittent cold stress is reversed by chronic antidepressant treatment. Int $J$ Neuropsychopharmacol 13: 997-1009.

Lei W, Omotade OF, Myers KR, Zheng JQ (2016). Actin cytoskeleton in dendritic spine development and plasticity. Soc Curr Opin Neurobiol 39: 86-92.

Lepack AE, Fuchikami M, Dwyer JM, Banasr M, Duman RS (2015). $\mathrm{BDNF}$ release is required for the behavioral actions of ketamine. Int J Neuropsychopharmacol 18: 1-6.

Li N, Lee B, Liu R, Banasr M, Dqyer JM, Iwata M et al (2010). mTOR-dependent dependent synapse formation underlies the rapid antidepressant effects of NMDA antagonists. Science 329: 959-964.

Li N, Liu RJ, Dwyer JM, Banasr M, Lee B, Son H et al (2011). Glutamate $\mathrm{N}$-methyl-D-aspartate receptor antagonists rapidly reverse behavioral and synaptic deficits caused by chronic stress exposure. Biol Psychiatry 69: 754-761.

Liston C, Miller MM, Goldwater DS, Radley JJ, Rocher AB, Hof PR et al (2006). Stress-induced alterations in prefrontal cortical dendritic morphology predict selective impairments in perceptual attentional set-shifting. J Neurosci 26: 7870-7874.

Lodge D, Mercier MS (2015). Ketamine and phencyclidine: the good, the bad and the unexpected. $\mathrm{Br} J$ Pharmacol 172: 4254-4276.

Luscher C, Nicoll RA, Malenka RC, Muller D (2000). Synaptic plasticity and dynamic modulation of the postsynaptic membrane. Nat Neurosci 3: 545-550.

Mabb AM, Je HS, Wall MJ, Robinson CG, Larsen RS, Qiang Y et al (2014). Triad3A regulates synaptic strength by ubiquitination of Arc. Neuron 82: 1299-1316.

Manji HK, Moore GJ, Rajkowska G, Chen G (2000). Neuroplasticity and cellular resilience in mood disorders. Mol Phychiatry 5: 578-593.

Merriam EPT, Haas ME, Keshavan GL, Keshavan MS, Sweeney JA (1999). Prefrontal cortical dysfunction in depression determined by wisconsin card sorting test performance. Am Psychiatry 156: 780-782.
Nicolas CS, Peineau S, Amici M, Csaba Z, Fafouri A, Javalet C et al (2012). The Jak/STAT pathway is involved in synaptic plasticity. Neuron 73: 374-390.

Olchanski N, McInnis Myers M, Halseth M, Cyr PL, Bockstedt L et al (2013). The economic burden of treatment-resistant depression. Clin Ther 35: 512-522.

Park S, Park JM, Kim S, Kim JA, Shepherd JD, Smith-Hicks CL et al (2008). Elongation factor 2 and fragile X mental retardation protein control the dynamic translation of Arc/Arg3.1 essential for mGluR-LTD. Neuron 59: 70-83.

Patton M, Morilak DA, Girotti M (2015). Involvement of the JAK/STAT3 signaling pathway in ketamine-induced synaptic plasticity. Soc Neurosci Abstr 41 Online program no. 410.09 .

Plath N, Ohana O, Dammermann B, Errington ML, Schmitz D, Gross C et al (2006). Arc/Arg3.1 is essential for the consolidation of synaptic plasticity and memories. Neuron 52: 437-444.

Porter RJ, Robinson LJ, Malhi GS, Gallagher P (2015). The neurocognitive profile of mood disorders-a review of the evidence and methodological issues. Bipolar Disord 17 Suppl 2: 21-40.

Proud CG (2009). mTORC1 signalling and mRNA translation. Biochem Soc Trans 37(Pt 1): 227-231.

Rogóz Z, Skuza G, Maj J, Danysz W (2002). Synergistic effect of uncompetitive NMDA receptor antagonists and antidepressant drugs in the forced swimming test in rats. Neuropharmacology 42: 1024-1030.

Steward O, Wallace CS, Lyford GL, Worley PF (1998). Synaptic activation causes the mRNA for the IEG Arc to localize selectively near activated postsynaptic sites on dendrites. Neuron 21: $741-751$

Shepherd JD, Bear MF (2011). New views of Arc, a master regulator of synaptic plasticity. Nat Neurosci 14: 279-284.

Waltereit R, Dammermann B, Wulff P, Scafidi J, Staubli U, Kauselmann G et al (2001). Arg3.1/Arc mRNA induction by $\mathrm{Ca} 2+$ and cAMP requires protein kinase $\mathrm{A}$ and mitogen-activated protein kinase/extracellular regulated kinase activation. J Neurosci 21: 5484-5493.

Zanos P, Moaddel R, Morris PJ, Georgiou P, Fischell J, Elmer GI et al (2016). NMDAR inhibition-independent antidepressant actions of ketamine metabolites. Nature 533: 481-486.

Zarate CA, Jaskaran B, Singh MD, Carlson PJ (2006). A randomized trial of an n-methyl-d-aspartate antagonist in treatment-resistant major depression. Arch Gen Psychiatry 63: 856-864.

Zunszain PA, Horowitz MA, Cattaneo A, Lupi MM, Pariante CM (2013). Ketamine: synaptogenesis, immunomodulation and glycogen synthase kinase- 3 as underlying mechanisms of its antidepressant properties. Mol Psychiatry 18: 1236-1241. 